\title{
Advanced Cardiovascular Support in Refractory Shock
}

\author{
Ashwin Neelavar Udupa, Rajesh Mohan Shetty ${ }^{1}$ \\ Department of Anaesthesiology and Critical Care, Kasturba Medical College Hospital, Manipal, 'Department of Critical Care Medicine, Manipal Hospital, Whitefield, \\ ITPL Road, Bengaluru, Karnataka, India
}

\section{Abstract}

"Shock" is a term that is used to signify inadequate tissue perfusion and cellular oxygenation. The basic principle of treating shock is restoring tissue perfusion and adequate cellular oxygenation. Resuscitation from shock is achieved using a combination of fluid therapy, inotropes, and vasopressors. Refractory shock has been defined as requirement of noradrenaline infusion of $>0.5 \mu \mathrm{g} / \mathrm{kg} / \mathrm{min}$ despite adequate volume resuscitation. Inability to use oxygen damages the cellular machinery and if not restored in time, shock can become irreversible. Mortality in these patients is very high, and the assessment and management of these patients requires a much more aggressive approach for survival. This article will focus on the management of refractory shock.

Keywords: Hypotension, inotropes, shock, tissue perfusion, vasopressors

\section{INTRODUCTION}

"Shock" is a term that is used to signify inadequate tissue perfusion and cellular oxygenation. Nearly one-third of patients in intensive care unit suffer from circulatory shock. ${ }^{[1]}$ Resuscitation from shock is achieved using a combination of fluid therapy, inotropes, and vasopressors. The basic principle of treating shock is restoring tissue perfusion and adequate cellular oxygenation. Inability to use oxygen damages the cellular machinery and if not restored in time, shock can become irreversible.

A patient can present with shock due to a multitude of reasons, and they have been classified into four types as follows: hypovolemic, cardiogenic, obstructive, and distributive. ${ }^{[1]}$

\section{Hypovolemic shock}

Hypovolemic shock is a result of inadequate circulating blood volume resulting from either blood loss or dehydration. The management strategy for hypovolemic shock is a rapid restoration of intravascular circulating volume by fluid therapy as well as hemorrhage control. The diagnostic workup of the patient in hypovolemic shock should be initiated while fluid resuscitation is on. An arterial line should be inserted at the earliest convenient time. If a patient with known hemorrhagic shock fails to respond to fluid therapy and blood transfusions, all efforts should be made to check whether that hemorrhage is still continuing. It is possible that hemorrhage

\begin{tabular}{|l|l|}
\hline \multicolumn{2}{|c|}{ Access this article online } \\
\hline Quick Response Code: & Website: \\
& www.ijrconline.org \\
\cline { 2 - 2 } & \\
&
\end{tabular}

that was previously controlled may have recurred due to the displacement of a clot.

\section{Cardiogenic shock}

Cardiogenic shock may be due to inadequate pumping function of the heart resulting in low cardiac output and inadequate tissue oxygen delivery $\left(\mathrm{DO}_{2}\right)$. Evaluation of the patient may reveal altered mental status, evidence of impaired organ perfusion, and elevated blood lactate levels. The most common cause of acute onset of cardiogenic shock is myocardial infarction, the treatment of which is reperfusion therapy either mechanically (primary transcutaneous coronary angioplasty) or chemically (thrombolysis).

\section{Obstructive shock}

Obstructive shock is due to obstruction of the blood flow to or from the heart. Examples include tension pneumothorax, cardiac tamponade, or pulmonary embolism. This group of patients are generally in extremis and the shocked state improves after the causative obstruction is corrected. Management strategy of obstructive shock is to relieve the obstruction. Tension pneumothorax is treatable with a needle thoracostomy followed by tube thoracostomy. Cardiac

Address for correspondence: Dr. Ashwin Neelavar Udupa, Department of Anaesthesiology and Critical Care, Kasturba Medical College, Manipal Academy of Higher Education, Manipal, Karnataka, India. E-mail: ashwinudupa@gmail.com

This is an open access journal, and articles are distributed under the terms of the Creative Commons Attribution-NonCommercial-ShareAlike 4.0 License, which allows others to remix, tweak, and build upon the work non-commercially, as long as appropriate credit is given and the new creations are licensed under the identical terms.

For reprints contact: reprints@medknow.com

How to cite this article: Udupa AN, Shetty RM. Advanced cardiovascular support in refractory shock. Indian J Respir Care 2018;7:67-72. 
Udupa and Shetty: Advanced cardiovascular support

tamponade will require emergency pericardial drainage. Reinfusion of the blood drained from the pericardium into a peripheral vein may be done if the patient is hemodynamically unstable due to injury to the myocardium. Subsequently, this may require surgical exploration to control the bleeding site. Pulmonary thromboembolism is treated with thrombolysis, whereas treatment of other forms of pulmonary embolism (fat, air, or amniotic fluid) is only supportive. Major pulmonary embolism, irrespective of etiology is difficult to treat and is frequently fatal.

\section{Distributive shock}

Distributive shock is an abnormality in the blood flow distribution in the smallest blood vessel resulting in inadequate blood supply to the body tissues and vital organs. This occurs due to severe sepsis or systemic inflammatory response. Sepsis is defined as syndrome of life-threatening organ dysfunction (Sepsis-related organ function assessment score of 2 or more) as a result of the dysregulated host response to infection. ${ }^{[2]}$ Septic shock is a subset of patients with sepsis with cellular/metabolic dysfunction, circulatory collapse and a higher risk of mortality. Source control, cultures, and empirical antibiotic therapy form a significant part of the initial treatment along with emergent supportive management such as intravascular volume status assessment and replenishment, vasopressor, and inotropic support.

Although different types of shock may begin as discrete entities, one may merge into another as the condition progresses, especially in the critically ill patient. It is possible that a patient has more than one type of shock, for example, a patient with ischemic heart disease and low ejection fraction develops a severe infection and septic shock.

\section{Definition of Refractory Shock}

Refractory shock has been defined as requirement of noradrenaline infusion of $>0.5 \mu \mathrm{g} / \mathrm{kg} / \mathrm{min}$ despite adequate volume resuscitation. ${ }^{[3-5]}$ Mortality in these patients may be as high as $94 \%{ }^{[4-6]}$ and the assessment and management of these patients requires a much more aggressive approach for survival. This article will focus on the management of refractory shock.

\section{Pathophysiology of Refractory Shock}

Refractory shock is characterized by inadequate restoration of tissue perfusion. It could be related to central causes such as inadequate preload, low myocardial contractility or reduced afterload or peripheral causes such as anemia, maldistribution of cardiac output, disrupted microcirculation, or damaged cellular machinery. Distributive shock is a feature of all refractory shock despite its etiology. All forms of shock can trigger a systemic inflammatory response syndrome (SIRS) leading to release of various inflammatory mediators such as cytokine-induced nitric oxide synthase. ${ }^{[7,8]}$ Nitric oxide, a potent vasodilator is produced in high concentration in SIRS. Cellular hypoxia and acidosis lead to activation of potassium channels in the cell membranes leading to hyperpolarization and prevention of calcium accumulation in the cytosol. This leads to profound vasodilatation..$^{[9,10]}$ As mentioned earlier, cardiac dysfunction may coexist with hemorrhagic or septic shock.

\section{Management of Refractory Shock}

The term "refractory shock" is used when the tissue perfusion cannot be restored with the initial corrective measures employed. It can also be called "high vasopressor-dependent shock."

\section{Intravascular volume status assessment Clinical examination}

Patients with refractory shock may have features of inadequate perfusion such as hypotension (mean arterial blood pressure $<65 \mathrm{mmHg}$ ), tachycardia, cold peripheries, prolonged capillary refill time, and tachypnea consequent to the hypoxia and acidosis. Fever may be seen in septic shock. Other signs of hypoperfusion such as altered sensorium, hyperlactatemia, and oliguria may also be seen. These well-known signs of shock are not helpful in identifying whether the problem is at the pump (heart) or circuitry (vessels and tissues).

An educated guess after a careful review of the history and physical examination can be made but may not be entirely accurate. A wrong guess in a delicate patient can easily tip the balance, for example, administration of an intravenous bolus of fluid in a patient with low ejection fraction. Hypervolemia can be equally deleterious in these patients. These patients are often treated with diuretics with an aim to keep them "bone-dry," but they may actually need fluids. In such situations, more elaborate diagnostic modalities are required.

\section{Central venous pressure and pulmonary artery pressure}

There are no data to support the widespread practice of using central venous pressure (CVP) to guide fluid therapy. Experts in the field advice that this approach to fluid resuscitation should be abandoned. ${ }^{[11]}$ This is because there are so many factors that can influence the CVP, especially in critically ill patients on mechanical ventilation. Interest in pulmonary catheter aided assessment has waned as studies have shown no mortality benefit.

Monitoring of central venous $\left(\mathrm{S}_{\mathrm{cv}} \mathrm{O}_{2}\right)$ and mixed venous oxygen $\left(\mathrm{S}_{\mathrm{v}} \mathrm{O}_{2}\right)$ saturation has been found to be helpful. Goals of resuscitation include urine output of $>0.5 \mathrm{ml} / \mathrm{kg} / \mathrm{h}, \mathrm{S}_{\mathrm{cv}} \mathrm{O}_{2}$ of $>70 \%$ or $\mathrm{S}_{\mathrm{v}} \mathrm{O}_{2}>65 \%$, decrease in lactate concentration by $20 \%$ every 2 h (if initially elevated), packed cell transfusion if hematocrit is $<30 \%$ after fluid resuscitation with the above parameters not yet optimized and inotrope infusions. ${ }^{[12-14]}$

\section{Esophageal Doppler}

Esophageal Doppler is a minimally invasive method for the estimation of stroke volume, cardiac index, and corrected flow time curve. These indices have been incorporated into an algorithm to suggest fluid or vasopressor/inotropic 
Udupa and Shetty: Advanced cardiovascular support

requirement. ${ }^{[15]}$ The dependability of the values depends on the signals received from the probe. The presence of Ryle's tube can interfere with its readings. This is an expensive device and may not be freely available in the developing countries.

Bedside transthoracic echocardiography is a useful skill for an intensivist and holds great promise as a quick diagnostic modality in a shocked patient. ${ }^{[16]}$ Visual estimation of contractility of the left and right ventricle provides quick answers to questions about starting an inotrope or administering fluids. The bedside echocardiogram can also be used to assess a number of other dynamic indices of fluid responsiveness including stroke volume, cardiac output as well as the inferior vena cava (IVC) diameter. These parameters are very sensitive indicators of fluid responsiveness. Some experts believe fluid challenges or passive leg raising (PLR) maneuvers coupled with real-time stroke volume monitoring is the only accurate method of determining fluid responsiveness. A transthoracic echocardiogram is very useful but interpretation will depend on the echocardiographer, and the window obtained.

\section{Inferior vena caval diameter}

IVC dimension can be measured using the curvilinear low frequency probe or an echo probe of a portable ultrasound machine. It is a static variable which can be used to assess fluid responsiveness. Variations in the IVC diameter are a very sensitive indicator of the volume responsiveness in patients who are breathing spontaneously. IVC collapsibility has been studied in a number of studies and found to be a useful indicator of fluid status. The current literature shows better assessment of fluid responsiveness with a cutoff of $25 \%-48 \%$ IVC collapsibility. ${ }^{[17,18]}$ In patients receiving mechanical ventilation with high PEEP or low tidal volume or those who have varying respiratory pattern if breathing spontaneously, chronic right ventricular dysfunction/severe tricuspid regurgitation, right ventricular myocardial infarction, and intra-abdominal hypertension, IVC collapsibility may not be a reliable indicator of fluid responsiveness.

\section{Passive leg raise maneuver}

PLR is an indicator of fluid responsiveness when a dynamic assessment of stroke volume assessment is used. ${ }^{[19]} \mathrm{A}$ minimally invasive or noninvasive cardiac output monitor is used to measure the stroke volume in supine position at $30^{\circ}$ semi-recumbent position. Subsequently, head low position is given such that $45^{\circ}$ elevation is provided to the lower half of the body with head and chest at $0^{\circ}$. Cardiac output is measured in this position after 1-2 min. ${ }^{[20]}$ A PLR-induced increase in cardiac output of $10 \%$ or more is considered fluid-responsive status. ${ }^{[19]}$ This method may not be possible in all groups of patients (e.g., head injury and raised intraabdominal pressure) where alternative measurements of cardiac output may need to be employed.

\section{FloTrac/Vigileo}

This is another minimally invasive monitor that uses the arterial waveform to estimate the cardiac index, stroke volume, and fluid responsiveness using a dynamic variable such as stroke volume variation (SVV). The available literature now shows the estimation of fluid responsiveness is too inaccurate in the third generation monitors. ${ }^{[21,22]}$ The latest version of Flotrac is, however, the fourth generation.

\section{Pulse index continuous cardiac output}

This method uses femoral arterial line and central line to estimate the cardiac index. It is one of the dynamic indicators of fluid responsiveness and employs pulse contour analysis. However, it has not shown to improve outcome as compared to CVP-based fluid management. ${ }^{[23]}$

Most of these less invasive cardiac monitors measure the stroke volume and the cardiac output in addition to dynamic indices of fluid responsiveness including the SVV and pulse pressure variability (PPV). An increase in SVV or PPV $>12 \%-13 \%$ is indicative of a fluid responsive status [Figure 1]. The SVV and the PPV help in evaluating the patient's position on the Frank-Starling curve. As long as the PPV or SVV is $>13 \%$, the patient is on the steep part of the Frank-Starling curve, and the patient would respond to a fluid bolus by improving the stroke volume and cardiac output [Figure 1]. ${ }^{[24]}$

It is important to note that cardiac output monitors based on pulse contour analysis may be affected by the presence of arrhythmias and severe refractory vasodilatation (vasoplegia). The SVV measurements require that the patient be ventilated with a tidal volume of at least $8 \mathrm{ml} / \mathrm{kg}$, whereas low-tidal volume ventilation is commonly used in these patients for lung protection.

In summary, hemodynamic monitoring seems to be trending from invasive to minimally invasive or noninvasive, from static to dynamic, from intermittent to continuous and from pressure to volume and flow-related measurements. Various recent meta-analyses have identified that the cardiac output

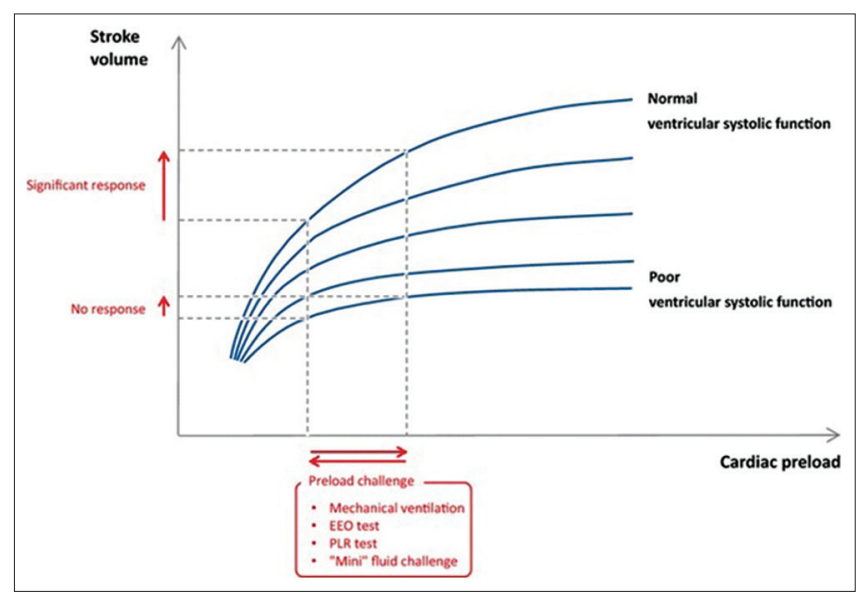

Figure 1: Frank-Starling relationship. Ventricular systolic function is depicted by the slope of the Frank Starling curve. Response to a dynamic test such as mechanical ventilation, fluid (preload) challenge, passive leg raising, differs in a normal functioning heart, and poorly functioning one. The resulting change in the stroke volume will indicate if further fluid will be helpful. EEO: end expiratory occlusion, PLR: passive leg raising, mini fluid challenge refers to $100 \mathrm{ml}$ fluid bolus. 
Udupa and Shetty: Advanced cardiovascular support

changes to PLR test as one of the most sensitive tests for fluid responsiveness with high specificity. ${ }^{[19]}$ Ultrasound and echocardiography have increasingly been utilized in hemodynamic assessment given noninvasiveness, bedside availability, simplicity, and lack of need for prolonged training. Minimally invasive or noninvasive monitors are inferior at this point in time due to heterogeneity, lack of validity, and proof of evidence by large randomized trials. Task force of the European society of intensive care medicine consensus statement recommends not to use a single variable for the diagnosis and/or management of shock. ${ }^{[25]}$

\section{Intravascular volume replenishment}

Hypovolemia should be corrected before initiating the inotropic or vasopressor support. SSC 2016 guidelines recommend initial fluid resuscitation with $30 \mathrm{~mL} / \mathrm{kg}$ of crystalloid within the first $3 \mathrm{~h}$ for patients in septic shock. ${ }^{[2]}$ Many patients will require more fluids than this, and for this group, further fluids are given preferably based on clinical and noninvasive cardiac output measurements. Currently, there is no evidence of benefit between crystalloids and colloids as resuscitation fluid of choice. ${ }^{[26]}$ Use of hydroxyethyl starch in septic shock is associated with increased incidence of renal replacement therapy. ${ }^{[27]}$

\section{Vasopressors and inotropic support}

Vasopressors are medications which increase vasomotor tone and thereby enhance venous return resulting in an increase in the cardiac output. They are used when the fluid resuscitation is considered to be adequate, and the systemic vascular resistance is judged to be low. If they are started as temporizing measure before fluid resuscitation is complete, all efforts should be made to ensure that this situation is corrected early. Inappropriate vasopressor therapy will further hamper oxygenation to the tissues leading to worsening of metabolic acidosis suggesting anaerobic metabolism. Inotropes increase the myocardial contractility and thus, the cardiac output. Their use is justified when the myocardial contractility is low.

The use of vasopressors is appropriate when the systolic blood pressure drops more than $30 \%$ as compared to the baseline or mean arterial pressure (MAP) is below $65 \mathrm{mmHg}$, and vasodilatation is the cause. Patients with hypertension require a higher MAP to maintain their organ perfusion. ${ }^{[28]}$ Individual vasoactive agents and their dose range are enlisted in Table $1 .{ }^{[28]}$

\section{Noradrenaline (norepinephrine)}

Noradrenaline is an alpha adrenergic agonist with less beta-agonistic effects. Noradrenaline increases MAP due to its vasoconstrictive effects, with stable or a slight decrease in the heart rate. Noradrenaline remains the first choice vasopressor to treat patients with septic shock. There is no significant difference in outcomes between any of the inotropes or vasopressors including adrenaline and noradrenaline.

\section{Vasopressin}

Vasopressin should be used in hypotensive cases where the cardiac function is good. The dose should not exceed $0.04 \mathrm{U} / \mathrm{min} \cdot{ }^{[1]}$ Most of the data regarding vasopressin support a sparing effect on norepinephrine dose, and there is uncertainty about the effect of vasopressin on mortality and morbidity.[29] Higher doses of vasopressin have been associated with cardiac, digital and splanchnic ischemia and should be reserved for situations in whom alternative vasopressors have failed. ${ }^{[30]}$

\section{Adrenaline (epinephrine)}

Adrenaline has action on both beta- and alpha-receptors. At lower doses, the drug causes an increase in cardiac output by a combination of an increase in contractility and peripheral vasoconstriction. At higher doses, the vasoconstrictive effects of the drug predominate. Adrenaline causes a rise in $\mathrm{DO}_{2}$ as well as the consumption $\left(\mathrm{VO}_{2}\right)$. Adrenaline may be used alternatively or in addition to noradrenaline. Even though adrenaline may have deleterious effects on the splanchnic circulation, clinical trials do not reveal worsening of clinical outcomes. ${ }^{[31]}$ However, increased aerobic lactate production through stimulation of skeletal muscle $\beta_{2}$-adrenergic receptors may preclude the use of lactate clearance to guide resuscitation.

\section{Dopamine}

Dopamine used as an alternative to noradrenaline when a rise in heart rate is desired (such as bradycardia and with low risk of tachyarrhythmias). Dopamine may give rise to certain unwanted endocrine side effects with reduction in prolactin secretion leading to immunosuppression ${ }^{[1]}$ Dopamine

Table 1: Comparison of vasoactive agents. Reprinted after permission from reference

\begin{tabular}{|c|c|c|c|c|c|c|}
\hline & \multirow[t]{2}{*}{ Dose } & \multicolumn{2}{|c|}{ Cardiac } & \multicolumn{3}{|c|}{ Peripheral vasculature } \\
\hline & & HR & Contractility & Vasoconstriction & Vasodilation & Dopaminergic \\
\hline Noradrenaline & $2-40 \mu \mathrm{g} / \mathrm{min}$ & + & ++ & ++++ & 0 & 0 \\
\hline \multirow[t]{2}{*}{ Dopamine } & $1-4 \mu \mathrm{g} / \mathrm{kg} / \mathrm{min}$ & + & + & 0 & + & ++++ \\
\hline & $4-20 \mu \mathrm{g} / \mathrm{kg} / \mathrm{min}$ & ++ & +++ & +++ & 0 & ++ \\
\hline Adrenaline & $1-20 \mu \mathrm{g} / \mathrm{min}$ & ++++ & ++++ & ++++ & +++ & 0 \\
\hline Phenylephrine & $20-200 \mu \mathrm{g} / \mathrm{min}$ & 0 & 0 & ++++ & 0 & 0 \\
\hline Vasopressin & $0.01-0.03 \mathrm{U} / \mathrm{min}$ & 0 & 0 & ++++ & 0 & 0 \\
\hline Dobutamine & $2-20 \mu \mathrm{g} / \mathrm{kg} / \mathrm{min}$ & ++ & ++++ & 0 & ++ & 0 \\
\hline Milrinone & $0.375-0.75 \mu \mathrm{g} / \mathrm{kg} / \mathrm{min}$ & + & +++ & 0 & ++ & 0 \\
\hline Levosimendan & $0.05-2 \mu \mathrm{g} / \mathrm{kg} / \mathrm{min}$ & + & +++ & 0 & ++ & 0 \\
\hline
\end{tabular}

HR: Heart rate, 0 : no effect,,,,$++++++++++:$ Refers to relative potency of individual vasoactive agents 
Udupa and Shetty: Advanced cardiovascular support

does not cause renal splanchnic vasodilation and its use for renoprotection is not recommended anymore. ${ }^{[1]}$

\section{Dobutamine}

Dobutamine increases the contractility of the heart and its rate, thereby increasing the cardiac output. However, there is no evidence of benefit with its use. Dobutamine is the first choice inotrope for patients with measured or suspected low cardiac output in the presence of adequate left ventricular filling pressure (or clinical assessment of adequate fluid resuscitation). Monitoring the response of indices of perfusion to measured increases in cardiac output is the best way to target such therapy. ${ }^{[32]}$

\section{Phosphodiesterase III inhibitors}

They increase the intracellular concentration of adenosine monophosphate (cyclic AMP) and improve the force of contraction without involving the adrenergic receptors. Milrinone and enoximone are commonly used drugs in this class and are referred to as lusitropic agents.

\section{Levosimendan}

Levosimendan increases cardiac myocyte calcium responsiveness and also opens ATP-dependent potassium channels, giving the drug both inotropic and vasodilatory properties. Trials comparing levosimendan with dobutamine are limited but show no clear advantage for levosimendan. ${ }^{[33]}$

\section{Other modalities of treatment Corticosteroids}

There is evidence that low dose corticosteroids improve vascular response to inotropes in patients with septic shock, especially when they are unresponsive to vasopressors. ${ }^{[34-37]}$ The dose recommended is $50 \mathrm{mg}, 6^{\text {th }}$ hourly. Adverse effects such as hyperglycemia, hypernatremia, and infection should be anticipated and treated accordingly. Addition of fludrocortisone does not provide any benefit. ${ }^{[38]}$

\section{Exotic therapies}

Many other therapies have been tried in the treatment of refractory shock including terlipressin (a long-acting analog of vasopressin), nitric oxide synthase inhibitors, methylene blue, glucose-insulin-potassium, and Giapreza. Terlipressin has the advantage of prolonged action compared to vasopressin but when given as a bolus, can reduce cardiac index. Thus, if terlipressin is used, it should be given as an infusion. ${ }^{[39]}$

Nitric oxide synthase inhibitors have not proven to be of any benefit. However, small studies have shown that methylene blue $(1.5-2 \mathrm{mg} / \mathrm{kg}$ ) followed by infusion reduces vasopressor requirements and has a mortality benefit. ${ }^{[40,41]}$ Larger studies would be needed to confirm this finding.

Glucose-insulin-potassium may improve cardiac function in these acutely sick patients even though its benefit could not be revealed in large trials. Similarly, aggressive control of fever is helpful by reducing oxygen and vasopressor requirements.
Giapreza is a synthetic angiotensin II vasoconstrictor. In December 2017, the Food and Drug Administration approved its use for treating low blood pressure resulting from septic shock. The most common adverse reactions reported are thromboembolic events $(>10 \%){ }^{[42]}$

Extracorporeal membrane oxygenation (ECMO) has been attempted in refractory septic shock to improve survival. A retrospective study in 2015 concluded that the ECMO could be considered in refractory septic shock with myocardial injury, but not after cardiopulmonary resuscitation. ${ }^{[43]}$ In a retrospective study of 42 institutes with 570 patients with severe respiratory failure with septic shock, ECMO showed no survival benefit. ${ }^{[44]}$

\section{Intra-aortic balloon pump}

Currently, there are only animal studies, and case reports in support of the use of (intra-aortic balloon pump [IABP]) for severe sepsis-induced cardiac dysfunction. ${ }^{[45]}$ Conclusive evidence is still lacking with regard to IABP in severe septic shock-associated cardiac dysfunction.

Cardiac support devices such as the left and right ventricular assist devices would be useful for patients in refractory cardiogenic shock as support and bridge devices to cardiac transplantation. They are not reported to have a role in any other form of shock.

\section{ConcLusion}

Early diagnosis and appropriate management can improve outcomes in shock. Different types of shock can coexist, and all forms of shock can become refractory, as evidenced by unresponsiveness to high-dose vasopressors. Understanding the principles of circulating volume optimization and vasoactive agents is the key to reverse the shocked state in a critically ill patient. It is recommended that apart from treating the cause, treatment decisions should be based on full comprehension of the patient condition. Monitoring and aggressive management of the condition are necessary to improve survival in these patients.

\section{Financial support and sponsorship}

Nil.

\section{Conflicts of interest}

There are no conflicts of interest.

\section{RefEREnCES}

1. Vincent JL, De Backer D. Circulatory shock. N Engl J Med 2013;369:1726-34.

2. Rhodes A, Evans LE, Alhazzani W, Levy MM, Antonelli M, Ferrer R, et al. Surviving sepsis campaign: International guidelines for management of sepsis and septic shock: 2016. Crit Care Med 2017;45:486-552.

3. Dünser MW, Mayr AJ, Ulmer H, Knotzer H, Sumann G, Pajk W, et al. Arginine vasopressin in advanced vasodilatory shock: A prospective, randomized, controlled study. Circulation 2003;107:2313-9.

4. Torgersen C, Dünser MW, Wenzel V, Jochberger S, Mayr V, Schmittinger CA, et al. Comparing two different arginine vasopressin 
Udupa and Shetty: Advanced cardiovascular support

doses in advanced vasodilatory shock: A randomized, controlled, open-label trial. Intensive Care Med 2010;36:57-65.

5. Torgersen C, Luckner G, Schröder DC, Schmittinger CA, Rex C, Ulmer $\mathrm{H}$, et al. Concomitant arginine-vasopressin and hydrocortisone therapy in severe septic shock: Association with mortality. Intensive Care Med 2011;37:1432-7.

6. Jenkins CR, Gomersall CD, Leung P, Joynt GM. Outcome of patients receiving high dose vasopressor therapy: A retrospective cohort study. Anaesth Intensive Care 2009;37:286-9.

7. Landry DW, Oliver JA. The pathogenesis of vasodilatory shock. N Engl J Med 2001;345:588-95.

8. Hochman JS. Cardiogenic shock complicating acute myocardial infarction: Expanding the paradigm. Circulation 2003;107:2998-3002.

9. Thiemermann C, Szabó C, Mitchell JA, Vane JR. Vascular hyporeactivity to vasoconstrictor agents and hemodynamic decompensation in hemorrhagic shock is mediated by nitric oxide. Proc Natl Acad Sci U S A 1993;90:267-71.

10. Levy B, Collin S, Sennoun N, Ducrocq N, Kimmoun A, Asfar P, et al. Vascular hyporesponsiveness to vasopressors in septic shock: From bench to bedside. Intensive Care Med 2010;36:2019-29.

11. Marik PE, Cavallazzi R. Does the central venous pressure predict fluid responsiveness? An updated meta-analysis and a plea for some common sense. Crit Care Med 2013;41:1774-81.

12. Dellinger RP, Levy MM, Rhodes A, Annane D, Gerlach H, Opal SM, et al. Surviving sepsis campaign: International guidelines for management of severe sepsis and septic shock: 2012. Crit Care Med 2013;41:580-637.

13. Rivers E, Nguyen B, Havstad S, Ressler J, Muzzin A, Knoblich B, et al. Early goal-directed therapy in the treatment of severe sepsis and septic shock. N Engl J Med 2001;345:1368-77.

14. Jansen TC, van Bommel J, Schoonderbeek FJ, Sleeswijk Visser SJ, van der Klooster JM, Lima AP, et al. Early lactate-guided therapy in Intensive Care Unit patients: A multicenter, open-label, randomized controlled trial. Am J Respir Crit Care Med 2010;182:752-61.

15. Singer M. Oesophageal doppler. Curr Opin Crit Care 2009;15:244-8

16. Marik PE, Baram M. Noninvasive hemodynamic monitoring in the Intensive Care Unit. Crit Care Clin 2007;23:383-400.

17. Corl KA, George NR, Romanoff J, Levinson AT, Chheng DB, Merchant RC, et al. Inferior vena cava collapsibility detects fluid responsiveness among spontaneously breathing critically-ill patients. J Crit Care 2017;41:130-7.

18. Preau S, Bortolotti P, Colling D, Dewavrin F, Colas V, Voisin B, et al. Diagnostic accuracy of the inferior vena cava collapsibility to predict fluid responsiveness in spontaneously breathing patients with sepsis and acute circulatory failure. Crit Care Med 2017;45:e290-7.

19. Monnet X, Marik P, Teboul JL. Passive leg raising for predicting fluid responsiveness: A systematic review and meta-analysis. Intensive Care Med 2016;42:1935-47.

20. De Backer D, Fagnoul D. Intensive care ultrasound: VI. Fluid responsiveness and shock assessment. Ann Am Thorac Soc 2014;11:129-36.

21. Marqué S, Gros A, Chimot L, Gacouin A, Lavoué S, Camus C, et al. Cardiac output monitoring in septic shock: Evaluation of the third-generation flotrac-vigileo. J Clin Monit Comput 2013;27:273-9.

22. Argueta E, Berdine G, Pena C, Nugent KM. FloTrac ${ }^{\circledR}$ monitoring system: What are its uses in critically ill medical patients? Am J Med Sci 2015;349:352-6.

23. Zhang Z, Ni H, Qian Z. Effectiveness of treatment based on piCCO parameters in critically ill patients with septic shock and/or acute respiratory distress syndrome: A randomized controlled trial. Intensive Care Med 2015;41:444-51.

24. Monnet X, Marik PE, Teboul JL. Prediction of fluid responsiveness: An update. Ann Intensive Care 2016;6:111.

25. Cecconi M, De Backer D, Antonelli M, Beale R, Bakker J, Hofer C, et al. Consensus on circulatory shock and hemodynamic monitoring. Task force of the European Society of Intensive Care Medicine. Intensive Care Med 2014;40:1795-815.

26. Annane D, Siami S, Jaber S, Martin C, Elatrous S, Declère AD, et al.
Effects of fluid resuscitation with colloids vs. crystalloids on mortality in critically ill patients presenting with hypovolemic shock: The CRISTAL randomized trial. JAMA 2013;310:1809-17.

27. Mutter TC, Ruth CA, Dart AB. Hydroxyethyl starch (HES) versus other fluid therapies: Effects on kidney function. Cochrane Database Syst Rev 2013;7:CD007594.

28. Hollenberg SM, Parrillo JE. Acute heart failure and shock. In: Crawford MH, DeMarco J, Paulus WJ, editors. Cardiology. $3^{\text {rd }}$ ed. Philadelphia: Mosby; 2010. p. 964.

29. Gordon AC, Mason AJ, Thirunavukkarasu N, Perkins GD, Cecconi M, Cepkova M, et al. Effect of early vasopressin vs. norepinephrine on kidney failure in patients with septic shock: The VANISH randomized clinical trial. JAMA 2016;316:509-18.

30. Dünser MW, Mayr AJ, Tür A, Pajk W, Barbara F, Knotzer H, et al. Ischemic skin lesions as a complication of continuous vasopressin infusion in catecholamine-resistant vasodilatory shock: Incidence and risk factors. Crit Care Med 2003;31:1394-8.

31. Avni T, Lador A, Lev S, Leibovici L, Paul M, Grossman A, et al. Vasopressors for the treatment of septic shock: Systematic review and meta-analysis. PLoS One 2015;10:e0129305.

32. Hollenberg SM, Ahrens TS, Annane D, Astiz ME, Chalfin DB, Dasta JF, et al. Practice parameters for hemodynamic support of sepsis in adult patients: 2004 update. Crit Care Med 2004;32:1928-48.

33. Gordon AC, Perkins GD, Singer M, McAuley DF, Orme RM, Santhakumaran S, et al. Levosimendan for the prevention of acute organ dysfunction in sepsis. N Engl J Med 2016;375:1638-48.

34. Sprung CL, Goodman S, Weiss YG. Steroid therapy of septic shock. Crit Care Clin 2009;25:825-34, x.

35. Annane D, Bellissant E, Sebille V, Lesieur O, Mathieu B, Raphael JC, et al. Impaired pressor sensitivity to noradrenaline in septic shock patients with and without impaired adrenal function reserve. Br J Clin Pharmacol 1998;46:589-97.

36. Annane D, Sébille V, Charpentier C, Bollaert PE, François B, Korach JM, et al. Effect of treatment with low doses of hydrocortisone and fludrocortisone on mortality in patients with septic shock. JAMA 2002;288:862-71.

37. Sprung CL, Annane D, Keh D, Moreno R, Singer M, Freivogel K, et al. Hydrocortisone therapy for patients with septic shock. N Engl J Med 2008;358:111-24.

38. COIITSS Study Investigators, Annane D, Cariou A, Maxime V, Azoulay E, D'honneur G, et al. Corticosteroid treatment and intensive insulin therapy for septic shock in adults: A randomized controlled trial. JAMA 2010;303:341-8.

39. Morelli A, Ertmer C, Rehberg S, Lange M, Orecchioni A, Cecchini V, et al. Continuous terlipressin versus vasopressin infusion in septic shock (TERLIVAP): A randomized, controlled pilot study. Crit Care 2009;13:R130.

40. Kirov MY, Evgenov OV, Evgenov NV, Egorina EM, Sovershaev MA, Sveinbjørnsson B, et al. Infusion of methylene blue in human septic shock: A pilot, randomized, controlled study. Crit Care Med 2001;29:1860-7.

41. Levin RL, Degrange MA, Bruno GF, Del Mazo CD, Taborda DJ, Griotti JJ, et al. Methylene blue reduces mortality and morbidity in vasoplegic patients after cardiac surgery. Ann Thorac Surg 2004;77:496-9.

42. Khanna A, English SW, Wang XS, Ham K, Tumlin J, Szerlip H, et al. Angiotensin II for the treatment of vasodilatory shock. N Engl J Med 2017;377:419-30.

43. Park TK, Yang JH, Jeon K, Choi SH, Choi JH, Gwon HC, et al. Extracorporeal membrane oxygenation for refractory septic shock in adults. Eur J Cardiothorac Surg 2015;47:e68-74.

44. Takauji S, Hayakawa M, Ono K, Makise H. Respiratory extracorporeal membrane oxygenation for severe sepsis and septic shock in adults: A propensity score analysis in a multicenter retrospective observational study. Acute Med Surg 2017;4:408-17.

45. Hiromi T, Toida C, Muguruma T, Hashiba K, Doi T, Nakamura K, et al. Two cases with intra-aortic balloon pumping use for severe septic cardiomyopathy. Acute Med Surg 2017;4:446-50. 